Sel ect i ve recovery of gol d, pal I adi um or $\mathrm{pl}$ at i num from aci di $\mathrm{c}$ waste sol ut $i$ on

\begin{tabular}{|l|l|}
\hline 著者 & $\begin{array}{l}\text { Hasegawa H r oshi, Bar ua Suman, Wakabayashi } \\
\text { Tonøya, Mashi o Asami, Naki Ter uya, Fur usho } \\
\text { Yoshi aki, Rahnan I snai I M M }\end{array}$ \\
\hline 著者別表示 & 長谷川 浩, 牧 輝弥 \\
\hline $\begin{array}{l}\text { j our nal or } \\
\text { publ i cat i on ti t l e }\end{array}$ & M cr ochem cal J our nal \\
\hline vol une & 139 \\
\hline page r ange & $174-180$ \\
\hline year & $2018-06-01$ \\
\hline URL & ht t p: //doi . or g/10. 24517/00051312 \\
\hline
\end{tabular}


The research article is originally published at Microchemical Journal An Elsevier Journal

https://www.journals.elsevier.com/microchemical-journal

The original publication is available at: http://dx.doi.org/10.1016/j.microc.2018.02.025

\section{Selective Recovery of Gold, Palladium, or Platinum from Acidic Waste}

\section{Solution}

Hiroshi Hasegawa, ${ }^{1, *}$ Suman Barua, ${ }^{2,3, *}$, Tomoya Wakabayashi ${ }^{2}$, Asami Mashio ${ }^{1}$, Teruya Maki $^{1}$, Yoshiaki Furusho ${ }^{4}$, Ismail M. M. Rahman ${ }^{5, *}$

${ }^{1}$ Institute of Science and Engineering, Kanazawa University, Kakuma, Kanazawa 920-1192, Japan

${ }^{2}$ Graduate School of Natural Science and Technology, Kanazawa University, Kakuma, Kanazawa 920-1192, Japan

${ }^{3}$ Department of Applied Chemistry and Chemical Engineering, University of Chittagong, Chittagong 4331, Bangladesh

${ }^{4}$ GL Sciences Inc., Nishishinjuku 6-22-1, Shinjuku, Tokyo 163-1130, Japan

${ }^{5}$ Institute of Environmental Radioactivity, Fukushima University, 1 Kanayagawa, Fukushima City, Fukushima 960-1296, Japan

*Author(s) for correspondence.

E-mail: hhiroshi@se.kanazawa-u.ac.jp (HH); sumanjoara@cu.ac.bd (SB);

immrahman@ipc.fukushima-u.ac.jp or i.m.m.rahman@gmail.com (IMMR) 


\section{Abstract}

End-of-life electrical and electronic equipment is the potential secondary resource for economically-viable precious metals (PMs), e.g., gold (Au), palladium (Pd), or platinum (Pt). The hydrometallurgical processes produce acidic leachates during the recovery of PMs from waste sources, while the selective recovery of $\mathrm{Au}, \mathrm{Pd}$, or Pt from such a matrix is challenging either due to the chemical similarities of elements or complexities in the sources and matrices. A total of nine solid-phase extraction (SPE) systems, all claimed to designed for separation of PMs from complex matrices, was evaluated at varying solution $\mathrm{pH}$ ( $\leq 2$ to 10 ) based on the selectivity towards Au, Pd, or Pt. The observation was used to develop a technique for selective $\mathrm{Au}, \mathrm{Pd}$, or Pt separation from acidic waste solutions using a macrocycle-equipped SPE. The feed solution flow-rates, eluent-type or compositions has been optimized to achieve maximum separation efficiency of the target analytes. The relative affinity of the macrocycles in solid-phase toward the ions $(\mathrm{Pd}>\mathrm{Au}>\mathrm{Pt})$ is the core phenomenon of the proposed technique, and the host-guest type interaction is expected to be more stable than the resinbased separation processes. Furthermore, application of the macrocycle-equipped SPE system is advantageous regarding economics as it minimizes the impact of coexisting ions in the matrix and provides unaltered separation performance for several loading-elution cycles.

\section{Keywords}

Solid-phase extraction; Supramolecular chemistry; Selective separation; Precious metals 


\subsection{Introduction}

Waste of electrical and electronic equipment (WEEE) become an issue of concern [1] primarily due to the exponential increase in their varieties, volumes, and origins [2], and being a potential source of hazards to the environment [3] and health [4, 5]. The fast-paced innovations of electronic products not only decrease the overall life-span [6] but also cause an imbalance in the supply-demand ratio of raw materials, especially precious metals (PMs) that are essential for these advanced devices but low in natural abundances [7]. The content of PMs in WEEE was assumed to be becoming higher than that of the ore itself [7], which indicates the environmental and economic significance of recycling of such wastes [3, 8, 9]. Recycling of PMs from WEEE is typically combined with mechanical pretreatments to segregate the value-contained components, such as printed-circuit-boards (PCBs), followed by hydrometallurgical treatments through leaching [10,11]. Aqua regia and mineral acids, e.g., hydrochloric acid ( $\mathrm{HCl})$, nitric acid $\left(\mathrm{HNO}_{3}\right)$ and sulfuric acid are used for the dissolution of PMs from WEEE-components [12]. Such acidic leachates are further treated for the recovery of PMs using conventional separation techniques, e.g., solvent extraction [13, 14], membrane filtration [15], cementation [16, 17], ion exchange [18, 19], adsorption [20, 21], and so forth.

In terms of the economic incentive, gold (Au) has the highest value among the recoverable PMs in WEEE, seconded by palladium (Pd) [22]. The physical and chemical properties of Pd has similarity with platinum (Pt), which also widely used in electrical devices and catalytic applications [20, 23]. Selective separation of Pd or Pt from the aqueous matrix has been challenging because of the coordination order between extractants and elements that occur as follows: $\mathrm{Pd}(\mathrm{II})>\mathrm{Pt}(\mathrm{II})>\mathrm{Pt}(\mathrm{IV})[23,24]$. A comparable separation efficiency for the $\left[\mathrm{PdCl}_{4}\right]$ ${ }^{2-}$ and $\left[\mathrm{PtCl}_{6}\right]^{2-}$, the chloro-complexes of Pd and Pt in $\mathrm{HCl}$, has also been observed during the ion-pair separation [23-25]. The Pd or Au in WEEE also remain co-mingled and challenging 
to collect selectively due to the complexity of the source, or coexisting elements and alloys at varying compositions and concentrations in the matrices [10].

In the current work, a technique for the selective separation of $\mathrm{Au}, \mathrm{Pd}$, or Pt from the acidic waste solution using macrocycle-equipped solid-phase extraction (SPE) system is proposed. Some similar SPE-variants were evaluated regarding the selective retention of $\mathrm{Au}, \mathrm{Pd}$, or $\mathrm{Pt}$ along with other critical factors for separation. The unique feature of the proposed technique, other than using an ion-selective SPE, is the non-destructive approach for the rapid recovery of the $\mathrm{Au}, \mathrm{Pd}$, or Pt from the acidic waste solution.

\subsection{Experimental}

\subsection{Materials}

\subsubsection{Instruments}

The iCAP 6300 ICP-OES (inductively coupled plasma optical emission spectrometer) from Thermo Fisher Scientific (Waltham, MA) was used for multi-element analysis. The EMT duo quartz torch in ICP-OES used $1.15 \mathrm{~kW}$ radio frequency power. The plasma, auxiliary and nebulizer gas flow-rates, were respectively, maintained at $12,1.0$ and $0.5 \mathrm{~L} \mathrm{~min}^{-1}$. The integration time was $30 \mathrm{~s}$, and each measurement was an averaged value of three replicates. The GL-SPE vacuum manifold kit (GL Sciences, Tokyo, Japan) combining with the CAS-1 air pump (AS ONE, Osaka, Japan) was used for SPE treatments. The Navi F-52 pH meter from Horiba Instruments (Kyoto, Japan) was used for solution $\mathrm{pH}$ measurements. The Arium Pro automated water purification system from Sartorius Stedim Biotech GmbH (Göttingen, Germany) was used to obtain the ultrapure water of $>18.2 \mathrm{M} \Omega \mathrm{cm}^{-1}$ resistivities.

\subsubsection{Laboratory wares}

The laboratory wares used during the experiment are as follows: a) low-density polyethylene narrow-mouth reagent bottles from Nalgene (Rochester, NY); (b) polypropylene DigiTUBE 
(screw-capped) from SCP Science (Quebec, Canada); (c) polyethylene Spitch Tube (screwcapped); (d) polypropylene volumetric flasks from AS ONE (Osaka, Japan), and micropipette tips from Nichiryo (Tokyo, Japan). All the laboratory wares were pre-cleaned by sequential overnight soaking in the Scat 20X-PF alkaline detergent (Nacalai Tesque, Kyoto, Japan), rinsing with ultrapure water, nightlong dipping in $\mathrm{HCl}\left(4 \mathrm{~mol} \mathrm{~L}{ }^{-1}\right)$ (Kanto Chemical, Tokyo, Japan) followed by thorough washing with ultrapure water.

\subsubsection{Reagents}

Analytical grade reagents were used throughout without any further treatment. Analytical standards (1000 $\mathrm{mg} \mathrm{L}^{-1}$ ) of Au, Pd, and Pt from Kanto Chemical (Tokyo, Japan) were diluted to prepare working solutions. Strontium chloride hexahydrate, barium chloride dihydrate, nickel nitrate, ammonium chloride (Kanto Chemical, Tokyo, Japan), cobalt chloride hexahydrate (Wako Pure Chemical Industries, Osaka, Japan), sodium chloride, potassium chloride, magnesium nitrate hexahydrate, calcium chloride dihydrates, (Nacalai Tesque, Kyoto, Japan) were used to prepare the simulated mixed matrix. Ammonium chloride, $\mathrm{HCl}$, sodium hydroxide $(\mathrm{NaOH})$ and thiourea, all procured from Kanto Chemical (Tokyo, Japan), were the other reagents used in the experiment.

2-(N-Morpholino)ethanesulfonic acid hydrate (MES) from Sigma-Aldrich (St. Louis, MO), 4(2-Hydroxymethyl)-1-piperazinyl)ethanesulfonic acid (HEPES) from Nacalai Tesque (Kyoto, Japan) and $N$-(tris(hydroxymethyl)methyl)-3-amino-propane sulfonic acid (TAPS) from MP Biomedicals (Solon, $\mathrm{OH}$ ) were used as buffer reagents to maintain solution $\mathrm{pH}$, respectively in the range of 3-5, 6-8 and 9-10. The solution $\mathrm{pH} \leq 2$ was achieved with concentrated $\mathrm{HCl}$, while $\mathrm{HCl}$ or $\mathrm{NaOH}\left(1 \mathrm{~mol} \mathrm{~L}^{-1}\right)$ was added to the solution for the adjustment of a specific $\mathrm{pH}$ from 2 to 10. 


\subsubsection{Certified reference material (CRM) and real sample}

ERM-CA713, a CRM for trace elements in wastewater, from European Commission's Joint Research Centre (Geel, Belgium), and plating process-waste solution supplied by Sasaki Chemical (Kyoto, Japan) was used for the method validation.

\subsubsection{SPE systems}

Column-packed (3 mL) SPE systems (particle mesh size, 60-100; density, 0.4 g mL ${ }^{-1}$; Fixedbed SPE-particle volume, 500 mg) of AnaLig PM-series (PM-01, PM-02, PM-03, PM-05, PM-06, PM-07, and PM-08) and AnaLig Pd-series (Pd-01 and Pd-02) as supplied by GL Sciences (Tokyo, Japan) were used. The SPE systems described to be equipped with macrocycles attached to the silica-gel base support [26] and claimed to possess selectivity towards a specific ion or group of ions from mixed matrices [27].

\subsection{Methods}

\subsubsection{Separation of ions}

The MRT-SPE systems are evaluated for the separation of ions from the simulated waste matrix, with the objective to optimize the operating conditions, e.g., $\mathrm{pH}$, flow-rates, eluent, and so forth. A complete cycle of SPE-operation includes five phases: rinsing or regeneration, conditioning, loading, pre-elution wash, and elution. The rinsing or regeneration of MRTSPEs was conducted using $\mathrm{HCl}\left(6 \mathrm{~mol} \mathrm{~L}{ }^{-1} ; 5 \mathrm{~mL}\right)$ followed by ultrapure water $(10 \mathrm{~mL})$. The conditioning of SPE-columns for maintaining the desired $\mathrm{pH}$ was achieved by passing MES, HEPES, or TAPS buffer solutions $\left(0.1 \mathrm{~mol} \mathrm{~L}^{-1}\right.$; 20 to $\left.50 \mathrm{~mL}\right)$. The loading phase aided the retention of target ions $(\mathrm{Au}, \mathrm{Pd}$, and $\mathrm{Pt}$ ) from feed solution ( $\geq 3 \mathrm{~mL}$ ) onto the elementselective SPE-particles (PM- or Pd-series) from the solution charged into the columns. The pre-elution wash phase (ultrapure water; $\geq 3 \mathrm{~mL}$ ) eliminated any remaining feed solution from the SPE-columns. The elution step back-extract the retained element with a suitable 
solvent (acid, base, or chelator) forming a liquid concentrate of the target element. The SPEoperation cycle restarts with regeneration step. The feed solution (B), and the effluents from the loading (S), pre-elution wash (W), and elution (E) phases were analyzed using ICP-OES. The retention and recovery rates of target elements at the SPEs were computed using Eq (1) and (2).

$$
\begin{aligned}
& \text { Extraction }(\%)=\frac{B-S-W}{B} \times 100 \\
& \text { Recovery }(\%)=\frac{E}{B-S-W} \times 100
\end{aligned}
$$

The corresponding $\mathrm{Au}, \mathrm{Pd}$, or Pt retention rates at different feed solution flow-rates or the recovery with different eluents at varying flow-rates or solvent-volumes has been studied to select the optimized separation performance.

\subsubsection{Determination of enrichment factor}

Enrichment factors for the Au, Pd, or Pt separation with the SPEs based on the corresponding selectivity behaviors were evaluated. The SPE-operation cycle was followed with the modification in $\mathrm{Au}, \mathrm{Pd}$, and Pt-containing feed solution volume (100 to $1000 \mathrm{~mL}$ ) in the loading phase. Optimized separation conditions as determined in the previous step was used. The eluent was analyzed using ICP-OES, and the enrichment factor was calculated using Eq (3):

$$
\text { Enrichment factor }=\frac{\text { Feed solution volume }}{\text { Eluent volume }}
$$

\subsection{Result and Discussion}

\subsection{Retention of Au, Pd, or Pt in SPEs}

\subsubsection{Effect of solution $\mathrm{pH}$}

The retention behavior of PM- or Pd-series SPEs at varying $\mathrm{pH}$ of 2 to 10 has been studied using a simulated mixed matrix solution containing $30 \mu \mathrm{mol} \mathrm{L}{ }^{-1} \mathrm{Au}, \mathrm{Pd}$, and Pt. The PMs 
( $\mathrm{Au}, \mathrm{Pd}$, or Pt) were retained quantitatively ( $\geq 95 \%$ ) up to $\mathrm{pH} \mathrm{4}$, except for PM-05, in every other SPEs included in the current work. The Au-extraction plummeted as the $\mathrm{pH}$ changed from acidic to neutral and after that, and the SPEs unable to capture Pd at solution $\mathrm{pH} \geq 8$. The PM-05 quantitatively captured Au and Pd from the acidic matrix, while the maximum of Pt contents ( $\geq 90 \%$ ) flow-through with the effluents from the loading (Figure 1). The decrease in metal retention at high pHs might be due to the formation of neutral and negative species at these pHs.

The PM-containing leaching solution from the hydro-metallurgical process usually of low $\mathrm{pH}$ [10]. Therefore, the retention of PMs in PM-05 from HCl-induced solution (2 to 6 mol L ${ }^{-1}$; $\mathrm{pH}<2$ ) was evaluated to observe Au or Pd extraction as high as 95\% or more, followed by a Pt-retention rate of 3\% or less (Figure 2). The $\mathrm{Au}, \mathrm{Pd}$, or Pt remains as chloro-complexes at low solution pHs, i.e., in the acidic matrix [28, 29]. Macrocycles can be designed for specific ion separations based on the size, configuration, charge, and so forth [27, 30, 31]. The differences in the retention behavior of PM-05 towards $\mathrm{Au}, \mathrm{Pd}$, or Pt might be attributable to the corresponding variations in the thermochemical radii (radius/nm) of the chloro-complexes of $\mathrm{Au}(0.288 \pm 0.019)$, Pd (0.313 \pm 0.019$)$, and Pt $(0.333 \pm 0.019)$ [32]. The higher efficiency of PM-05 SPE-system has thus been confirmed for retention of PMs from acidic wastewater.

\subsubsection{Effect of feed solution flow-rates}

The sample loading flow-rates in SPEs influences the retention of analytes, which supposed to be low enough to enable efficient extraction and adequately high to avoid excessive duration [33]. The feed solution flow-rates, as controlled using a stopcock in SPE-column and an auto-flow speed controller unit, was adjusted in the range of 1 to $180 \mathrm{~mL} \mathrm{~min}{ }^{-1}$ to evaluate the retention of $\mathrm{Au}, \mathrm{Pd}$, or $\mathrm{Pt}$ in $\mathrm{PM}-05$. The retention rate for $\mathrm{Au}$ or $\mathrm{Pd}$ was $\geq 95 \%$ 


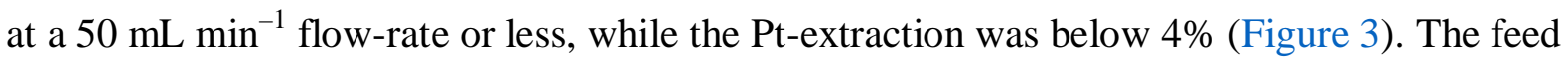
solution flow-rates, therefore, has been maintained $<50 \mathrm{~mL} \mathrm{~min}^{-1}$ for all the experiments.

\subsubsection{Effect of coexisting ions}

The retention of analytes in SPEs is often interfered due to the coexisting matrix components [33, 34]. The PM-containing components in WEEE, e.g., PCBs, include several elements at different proportions [35]. The selectivity towards Au, Pd, or Pt in PM-05 in the presence of common coexisting ions $\left(\mathrm{Na}^{+}, \mathrm{K}^{+}, \mathrm{Ba}^{+}, \mathrm{Mg}^{2+}, \mathrm{Ca}^{2+}, \mathrm{Ni}^{2+}, \mathrm{Sr}^{2+}, \mathrm{Co}^{2+}, \mathrm{Cu}^{2+}, \mathrm{Pb}^{2+}, \mathrm{Fe}^{3+}\right.$, and $\mathrm{Al}^{3+}$ ) was studied. Simulated solutions containing $30 \mu \mathrm{mol} \mathrm{L}{ }^{-1}$ each of $\mathrm{Au}$, Pd, or Pt was spiked with varying concentrations ( 3 to $300 \mathrm{mmol} \mathrm{L}^{-1}$ ) of different cations and treated in PM-05 at optimized conditions. An optimum tolerable concentration ratio (ion: analytes $=1 \times$ $10^{4}$ ) was computed in the presence of $\mathrm{Na}^{+}, \mathrm{K}^{+}, \mathrm{Ba}^{+}, \mathrm{Mg}^{2+}, \mathrm{Ca}^{2+}, \mathrm{Ni}^{2+}, \mathrm{Cu}^{2+}$ and $\mathrm{Pb}^{2+}$ in $\mathrm{Au}$; $\mathrm{Na}^{+}, \mathrm{K}^{+}, \mathrm{Ba}^{+}, \mathrm{Mg}^{2+}, \mathrm{Cu}^{2+}$ and $\mathrm{Pb}^{2+}$ in $\mathrm{Pd}$, while it is reduced by 10 times for $\mathrm{Co}^{2+}, \mathrm{Fe}^{3+}$ and $\mathrm{Al}^{3+}$ in $\mathrm{Au} ; \mathrm{Ca}^{2+}, \mathrm{Ni}^{2+}, \mathrm{Co}^{2+}, \mathrm{Fe}^{3+}$ and $\mathrm{Al}^{3+}$ in Pd (ion: analytes $=1 \times 10^{3}$ ) and 100 times for $\mathrm{Sr}^{2+}$ in Pd solutions (ion: analytes $=1 \times 10^{2}$ ) in PM-05 (Figure 4).

\subsubsection{Retention capacity}

The retention capacity of an SPE-sorbent determines the sorbent volume required for quantitative enrichment of an analyte from the matrix, is a useful analytical variable for SPEassisted separation [36, 37]. A simulated mixed matrix of $\mathrm{Au}$, Pd, or Pt $\left(0.5 \mathrm{mmol} \mathrm{L}^{-1}\right)$ in $\mathrm{HCl}$ $\left(1 \mathrm{~mol} \mathrm{~L}^{-1}\right.$ ) was used to evaluate the retention capacity of PM-05 SPE-system (Figure 5). The content of retained Au or Pd increased up to $140 \mathrm{~mL}$ feed solution followed by a gradual decrease of Au-retention, while Pd-retention continued until the saturation at $250 \mathrm{~mL}$ sample volume. The maximum Pd-retention capacity of PM-05 was computed as $0.22 \mathrm{mmol} \mathrm{g}^{-1}$ or 23 $\mathrm{mg} \mathrm{g}^{-1}$. The retained Au within the SPE was replaced with Pd at $>140 \mathrm{~mL}$ sample volume 
and entirely back-extracted with the feed solution volume of $\geq 250 \mathrm{~mL}$. Therefore, the retention capacity of PM-05 SPE-system was at the following order: $\mathrm{Pt}<\mathrm{Au}<\mathrm{Pd}$.

\subsection{Recovery of Au, Pd, or Pt from SPEs}

\subsubsection{Selection of eluent}

High enrichment factor in a selective separation process can be achieved using a solvent that could elute the analyte with a minimum volume and does not affect the determination of analytes [38, 39]. The effect of different solvents $\left(\mathrm{HNO}_{3}, \mathrm{NH}_{3}, \mathrm{HCl}\right.$, thiourea; $\left.1 \mathrm{~mol} \mathrm{~L}{ }^{-1}\right)$, and a mixture of thiourea in $\mathrm{HCl}\left(1: 0.5 \mathrm{~mol} \mathrm{~L}^{-1}\right)$ has been checked for the desorption of retained $\mathrm{Au}$ or Pd from PM-05 SPE-system. The recovery of analytes was notable with thiourea ( $\geq 82 \%$ ), while a quantitative elution ( $\geq 96 \%$ ) was observed for thiourea in $\mathrm{HCl}$ mix (Figure 6a). The effect of thiourea concentration with the mixtures of $0.5 \mathrm{~mol} \mathrm{~L}{ }^{-1} \mathrm{HCl}$ in the back extraction has also been studied. The recovery ratio was gradually increased with the increase of thiourea concentration, and remain unchanged at $\geq 1 \mathrm{~mol} \mathrm{~L}^{-1}$ (Figure 6b). Hence, 1: $0.5 \mathrm{~mol} \mathrm{~L}^{-1}$ mix of thiourea in $\mathrm{HCl}$ is used for further experiments. Acidic thiourea solution has been recommended as an eluent for the recovery of PMs from SPEs in other reported works as well [40, 41].

\subsubsection{Enrichment factor}

The enrichment factor for the separation of Au or Pd using PM-05 was checked using a simulated acidic waste solution containing $60 \mu \mathrm{g}$ Au and $650 \mu \mathrm{g}$ Pd in $\mathrm{HCl}\left(1 \mathrm{~mol} \mathrm{~L}^{-1}\right)$. The content of Au or Pd resembled that of a real plating-process waste solution. The feed solution volume was varied from 100 to $1000 \mathrm{~mL}$ with an upward interval of $100 \mathrm{~mL}$, and quantitative retention of $\mathrm{Au}$ or Pd was observed throughout. The retained ion was back-extracted using two $\mathrm{mL}$ of acidic thiourea solution $(1: 0.5=$ thiourea: $\mathrm{HCl})$ at an eluent flow rate of $1 \mathrm{~mL}$ 
$\min ^{-1}$. A maximum enrichment factor of 500 was, hence, computed with $<4 \%$ relative standard deviation that indicated sufficient accuracy and good precision.

\subsection{Protocol for selective separation of $\mathrm{Au}, \mathrm{Pd}$, or Pt}

A multi-step SPE-assisted protocol for the selective separation of Au, Pd, or Pt from the acidic aqueous matrix of the hydrometallurgical process was designed based on the retention behavior of PM-05, as described in Section 3.1.4. A mixed matrix containing $\mathrm{Au}, \mathrm{Pd}$, or Pt was allowed to pass through the SPE-system until the saturation point that allowed retention of only the Pd within SPE (step 1). The Au or Pt was collected in the effluents from the loading, which is further passed through the PM-05 to retain the Au within the SPE and to collect Pt as a component of the effluent (step 2). The retained elements in the solid phase of PM-05 at the operating steps 1 and 2 were quantitatively eluted using acidic thiourea solution (thiourea: $\mathrm{HCl}=1: 0.5$ ). The protocol is schematically illustrated in Figure 7 .

\subsection{Reusability of the SPE-system}

An SPE-assisted separation protocol would be economical if the SPE-system can be regenerated with negligible performance loss and reused [42, 43]. The macrocycle-equipped PM-05 system subjected to the repeated complete cycle of SPE-operation using a simulated acidic waste solution containing $\mathrm{Au}, \mathrm{Pd}$, or $\mathrm{Pt}\left(30 \mu \mathrm{mol} \mathrm{L}{ }^{-1}\right)$ in $\mathrm{HCl}\left(1 \mathrm{~mol} \mathrm{~L}^{-1}\right)$ matrix. The retention rate was $\geq 97 \pm 2 \%$ for Au or Pd after 100 cycles followed by a recovery rate of $\geq$ $98 \pm 3 \%$. Therefore, the PM-05 can sustain more than 100 loading and elution cycles without any loss of analytical performance.

\subsection{Accuracy and applications}

The accuracy of the proposed separation protocol for Au, Pd, or Pt was evaluated by analyzing simulated acidic waste matrix prepared using ERM-CA71, and real plating process-waste solution. The composition of the matrices and the recovery ratio for the target 

analytes after SPE-assisted treatment are shown in Table 1. The estimated recoveries of the target analytes were satisfactory (CRM: $\geq 95.1 \%$; plating process-waste solution: $\geq 97.8 \%$ ).

\subsection{Conclusion}

A protocol for the selective separation of $\mathrm{PMs}(\mathrm{Au}, \mathrm{Pd}$, or $\mathrm{Pt}$ ) from acidic matrix has been proposed using macrocycle-equipped PM-05 SPE-system. The retention ability of PM-05, which was varied in the following order: $\mathrm{Pd}>\mathrm{Au}>\mathrm{Pt}$, was used to develop the protocol. A negligible influence of feed solution flow-rates $\left(\leq 50 \mathrm{~mL} \mathrm{~min}^{-1}\right)$ and coexisting matrix ions was observed. A quantitative back extraction of $\mathrm{Au}$ or $\mathrm{Pd}$, retained in the PM-05, was possible using an eluent mix of thiourea in $\mathrm{HCl}(1: 0.5)$. The enrichment factor of the protocol for the selective separation of PMs was $\geq 500$, and the SPE-system successfully sustained 100-cycle of a complete SPE-operation. The method was validated using a CRM and real process-waste solution and could be considered as an environment-friendly economic option for the recovery of PMs from acidic leaching waste of the metallurgical process.

\section{Acknowledgement}

The research has partially been supported by Grants-in-Aid for Scientific Research (15H05118 and 17K00622)) from the Japan Society for the Promotion of Science. 


\section{References}

[1] O.A. Ogunseitan, J.M. Schoenung, J.-D.M. Saphores, A.A. Shapiro, The electronics revolution: From e-wonderland to e-wasteland, Science 326 (2009) 670-671.

[2] B.R. Babu, A.K. Parande, C.A. Basha, Electrical and electronic waste: A global environmental problem, Waste Manag. Res. 25 (2007) 307-318.

[3] R. Widmer, H. Oswald-Krapf, D. Sinha-Khetriwal, M. Schnellmann, H. Böni, Global perspectives on e-waste, Environ. Impact Asses. 25 (2005) 436-458.

[4] C. Frazzoli, O.E. Orisakwe, R. Dragone, A. Mantovani, Diagnostic health risk assessment of electronic waste on the general population in developing countries' scenarios, Environ. Impact Asses. 30 (2010) 388-399.

[5] A. Chen, K.N. Dietrich, X. Huo, S.M. Ho, Developmental neurotoxicants in e-waste: An emerging health concern, Environ. Health Perspect. 119 (2011) 431-438.

[6] M. Schmidt, A production-theory-based framework for analysing recycling systems in the e-waste sector, Environ. Impact Asses. 25 (2005) 505-524.

[7] C.R. Adhikari, D. Parajuli, H. Kawakita, K. Inoue, K. Ohto, H. Harada, Dimethylamine-modified waste paper for the recovery of precious metals, Environ. Sci. Technol. 42 (2008) 5486-5491.

[8] M.J. Realff, M. Raymond, J.C. Ammons, E-waste: An opportunity, Mater. Today 7 (2004) 40-45.

[9] M.M. Hossain, I.M.M. Rahman, Z.A. Begum, H. Hasegawa, An overview of toxic environmental releases from e-waste, In: Y.C. Li, B.L. Wang (Eds.) E-Waste: Management, Types and Challenges, Nova Science Publishers, Hauppauge, NY, USA, 2012, pp. 205-220.

[10] A. Behnamfard, M.M. Salarirad, F. Veglio, Process development for recovery of copper and precious metals from waste printed circuit boards with emphasize on palladium and gold leaching and precipitation, Waste Manag. 33 (2013) 2354-2363.

[11] S. Harjanto, Y. Cao, A. Shibayama, I. Naitoh, T. Nanami, K. Kasahara, Y. Okumura, K. Liu, T. Fujita, Leaching of Pt, Pd and Rh from automotive catalyst residue in various chloride based solutions, Mater. Trans. 47 (2006) 129-135.

[12] A. Tuncuk, V. Stazi, A. Akcil, E.Y. Yazici, H. Deveci, Aqueous metal recovery techniques from e-scrap: Hydrometallurgy in recycling, Miner. Eng. 25 (2012) 28-37. 
[13] M. Shamsipur, M. Ramezani, M. Sadeghi, Preconcentration and determination of ultra trace amounts of palladium in water samples by dispersive liquid-liquid microextraction and graphite furnace atomic absorption spectrometry, Microchim. Acta 166 (2009) 235-242.

[14] M. Shamsipur, M. Ramezani, Selective determination of ultra trace amounts of gold by graphite furnace atomic absorption spectrometry after dispersive liquid-liquid microextraction, Talanta 75 (2008) 294-300.

[15] X. Li, C. Zhang, R. Zhao, X. Lu, X. Xu, X. Jia, C. Wang, L. Li, Efficient adsorption of gold ions from aqueous systems with thioamide-group chelating nanofiber membranes, Chem. Eng. J. 229 (2013) 420-428.

[16] S. Aktas, Cementation of rhodium from waste chloride solutions using copper powder, Int. J. Miner. Process. 114-117 (2012) 100-105.

[17] H. Umeda, A. Sasaki, K. Takahashi, K. Haga, Y. Takasaki, A. Shibayama, Recovery and concentration of precious metals from strong acidic wastewater, Mater. Trans. 52 (2011) 1462-1470.

[18] B. Godlewska-Żylkiewicz, B. Leśniewska, U. Gąsiewska, A. Hulanicki, Ion-exchange preconcentration and separation of trace mounts of platinum and palladium, Anal. Lett. 33 (2000) 2805-2820.

[19] S. Shen, L. Guishen, T. Pan, J. He, Z. Guo, Selective adsorption of Pt ions from chloride solutions obtained by leaching chlorinated spent automotive catalysts on ion exchange resin Diaion WA21J, J. Colloid Interface Sci. 364 (2011) 482-489.

[20] M.H. Morcali, B. Zeytuncu, Investigation of adsorption parameters for platinum and palladium onto a modified polyacrylonitrile-based sorbent, Int. J. Miner. Process. 137 (2015) 52-58.

[21] H. Wang, C. Li, C. Bao, L. Liu, X. Liu, Adsorption and determination of Pd(II) and Pt(IV) onto 3'-nitro-4-amino azobenzene modified chitosan, J. Chem. Eng. Data 56 (2011) 4203-4207.

[22] X. Wang, G. Gaustad, Prioritizing material recovery for end-of-life printed circuit boards, Waste Manag. 32 (2012) 1903-1913.

[23] K. Matsumoto, S. Yamakawa, M. Jikei, Selective recovery of platinum(IV) from palladium(II)-containing solution using 4-(hexyloxy)aniline, Chem. Lett. 46 (2017) 22-24. 
[24] M.J. Cleare, P. Charlesworth, D.J. Bryson, Solvent extraction in platinum group metal processing, J. Chem. Technol. Biotechnol. 29 (1979) 210-224.

[25] Z. Hubicki, G. Wójcik, Studies of removal of platinum(IV) ion microquantities from the model solutions of aluminium, copper, iron, nickel and zinc chloride macroquantities on the anion exchanger Duolite S 37, J. Hazard. Mater. 136 (2006) 770-775.

[26] R.M. Izatt, S.R. Izatt, N.E. Izatt, K.E. Krakowiak, R.L. Bruening, L. Navarro, Industrial applications of molecular recognition technology to separations of platinum group metals and selective removal of metal impurities from process streams, Green Chem. 17 (2015) 2236-2245.

[27] I.M.M. Rahman, Z.A. Begum, H. Hasegawa, Selective separation of elements from complex solution matrix with molecular recognition plus macrocycles attached to a solid-phase: A review, Microchem. J. 110 (2013) 485-493.

[28] K. Fujiwara, A. Ramesh, T. Maki, H. Hasegawa, K. Ueda, Adsorption of platinum (IV), palladium (II) and gold (III) from aqueous solutions onto l-lysine modified crosslinked chitosan resin, J. Hazard. Mater. 146 (2007) 39-50.

[29] A.V. Pirogov, J. Havel, Determination of platinum, palladium, osmium, iridium, rhodium and gold as chloro complexes by capillary zone electrophoresis, J. Chromatogr. A 772 (1997) 347-355.

[30] J.S. Bradshaw, R.L. Bruening, K.E. Krakowiak, B.J. Tarbet, M.L. Bruening, R.M. Izatt, J.J. Christensen, Preparation of silica gel-bound macrocycles and their cationbinding properties, J. Chem. Soc., Chem. Commun. (1988) 812-814.

[31] R.M. Izatt, J.S. Bradshaw, R.L. Bruening, B.J. Tarbet, M.L. Bruening, Solid-phase extraction of ions using molecular recognition technology, Pure Appl. Chem. 67 (1995) 1069-1074.

[32] H.K. Roobottom, H.D.B. Jenkins, J. Passmore, L. Glasser, Thermochemical radii of complex ions, J. Chem. Educ. 76 (1999) 1570-1573.

[33] V. Camel, Solid phase extraction of trace elements, Spectrochim. Acta B 58 (2003) 1177-1233.

[34] H. Hasegawa, I.M.M. Rahman, Y. Umehara, H. Sawai, T. Maki, Y. Furusho, S. Mizutani, Selective recovery of indium from the etching waste solution of the flatpanel display fabrication process, Microchem. J. 110 (2013) 133-139. 
[35] J. Szałatkiewicz, Metals content in printed circuit board waste, Pol. J. Environ. Stud. 23 (2014) 2365-2369.

[36] B. Feist, Selective dispersive micro solid-phase extraction using oxidized multiwalled carbon nanotubes modified with 1,10-phenanthroline for preconcentration of lead ions, Food Chem. 209 (2016) 37-42.

[37] S. Barua, I.M. Rahman, I. Alam, M. Miyaguchi, H. Sawai, T. Maki, H. Hasegawa, Liquid electrode plasma-optical emission spectrometry combined with solid-phase preconcentration for on-site analysis of lead, J. Chromatogr. B 1060 (2017) 190-199.

[38] I.M.M. Rahman, Y. Furusho, Z.A. Begum, N. Izatt, R. Bruening, A. Sabarudin, H. Hasegawa, Separation of lead from high matrix electroless nickel plating waste solution using an ion-selective immobilized macrocycle system, Microchem. J. 98 (2011) 103-108.

[39] H. Hasegawa, I.M.M. Rahman, M. Nakano, Z.A. Begum, Y. Egawa, T. Maki, Y. Furusho, S. Mizutani, Recovery of toxic metal ions from washing effluent containing excess aminopolycarboxylate chelant in solution, Water Res. 45 (2011) 4844-4854.

[40] Q. Yi, R. Fan, F. Xie, H. Min, Q. Zhang, Z. Luo, Selective recovery of Au(III) and Pd(II) from waste PCBs using ethylenediamine modified persimmon tannin adsorbent, Procedia Environ. Sci. 31 (2016) 185-194.

[41] D. Li, X. Chang, Z. Hu, Q. Wang, Z. Tu, R. Li, Selective solid-phase extraction of trace $\mathrm{Au}(\mathrm{III}), \mathrm{Pd}(\mathrm{II})$ and $\mathrm{Pt}(\mathrm{IV})$ using activated carbon modified with 2,6diaminopyridine, Microchim. Acta 174 (2011) 131.

[42] I.M.M. Rahman, Y. Furusho, Z.A. Begum, A. Sabarudin, S. Motomizu, T. Maki, H. Hasegawa, Selective separation of some ecotoxic transition metal ions from aqueous solutions using immobilized macrocyclic material containing solid phase extraction system, Cent. Eur. J. Chem. 9 (2011) 1019-1026.

[43] I.M.M. Rahman, Z.A. Begum, M. Nakano, Y. Furusho, T. Maki, H. Hasegawa, Selective separation of arsenic species from aqueous solutions with immobilized macrocyclic material containing solid phase extraction columns, Chemosphere 82 (2011) 549-556. 
Table 1: Application of the proposed separation protocol for the selective recovery of $\mathrm{Au}, \mathrm{Pd}$, and Pt from Certified Reference Materials (CRM) and real plating waste solution $(n=3)$

\begin{tabular}{|c|c|c|c|c|c|c|}
\hline \multirow[t]{3}{*}{ Analyte } & \multicolumn{2}{|c|}{$\begin{array}{l}\text { Composition } \\
\left(\mu \mathrm{mol} \mathrm{L}{ }^{-1}\right)\end{array}$} & \multicolumn{2}{|c|}{$\begin{array}{l}\text { Added content } \\
\left(\mu \mathrm{mol} \mathrm{L}{ }^{-1}\right)\end{array}$} & \multicolumn{2}{|l|}{$\begin{array}{l}\text { Recovery } \\
\text { (\%) }\end{array}$} \\
\hline & ERM- & Plating & ERM- & Plating & ERM- & Plating \\
\hline & CA713 & waste & CA713 & waste & CA713 & waste \\
\hline $\mathrm{Au}$ & - & 0.3 & 5.2 & - & $95.1 \pm 1.0$ & $99.9 \pm 0.4$ \\
\hline $\mathrm{Pd}$ & - & 6.1 & 5.2 & - & $97.8 \pm 2.5$ & $97.8 \pm 1.0$ \\
\hline $\mathrm{Pt}$ & - & 0.1 & 5.2 & - & $98.1 \pm 0.8$ & $98.4 \pm 0.7$ \\
\hline
\end{tabular}

'-’ stands for 'not mentioned' or 'no added content.' 

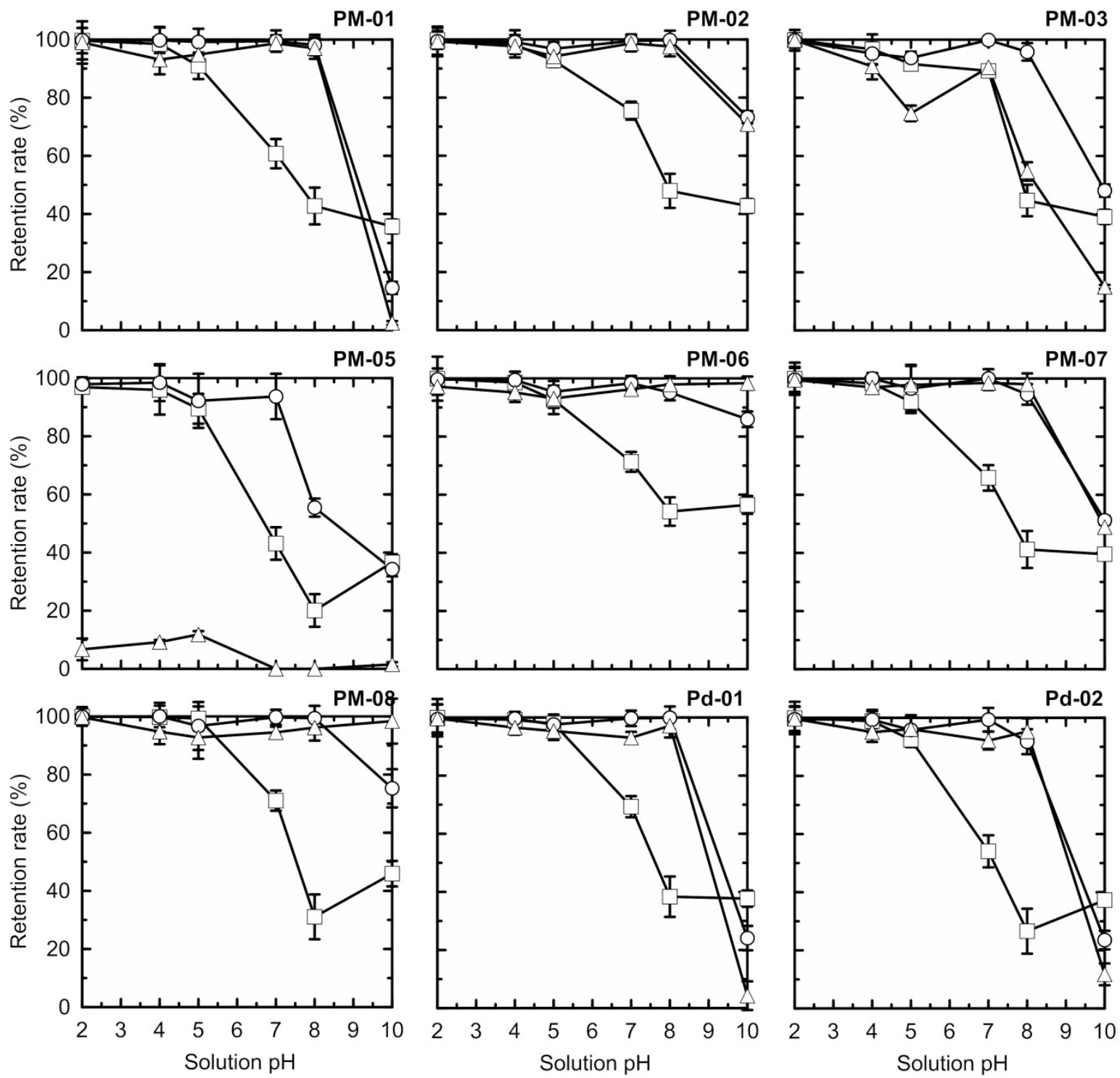

Figure 1: Retention of $\mathrm{Au}, \mathrm{Pd}$, or Pt in the SPE-systems. Feed solution, $\mathrm{Au}, \mathrm{Pd}$ and $\mathrm{Pt}$ (30 $\mu \mathrm{mol} \mathrm{L}{ }^{-1}$ ) in $\mathrm{H}_{2} \mathrm{O}$; solution $\mathrm{pH}, 2$ to 10 ; feed solution volume, $3 \mathrm{~mL}$; loading flow-rate, $3 \mathrm{~mL}$ $\min ^{-1}(n=3)$ 

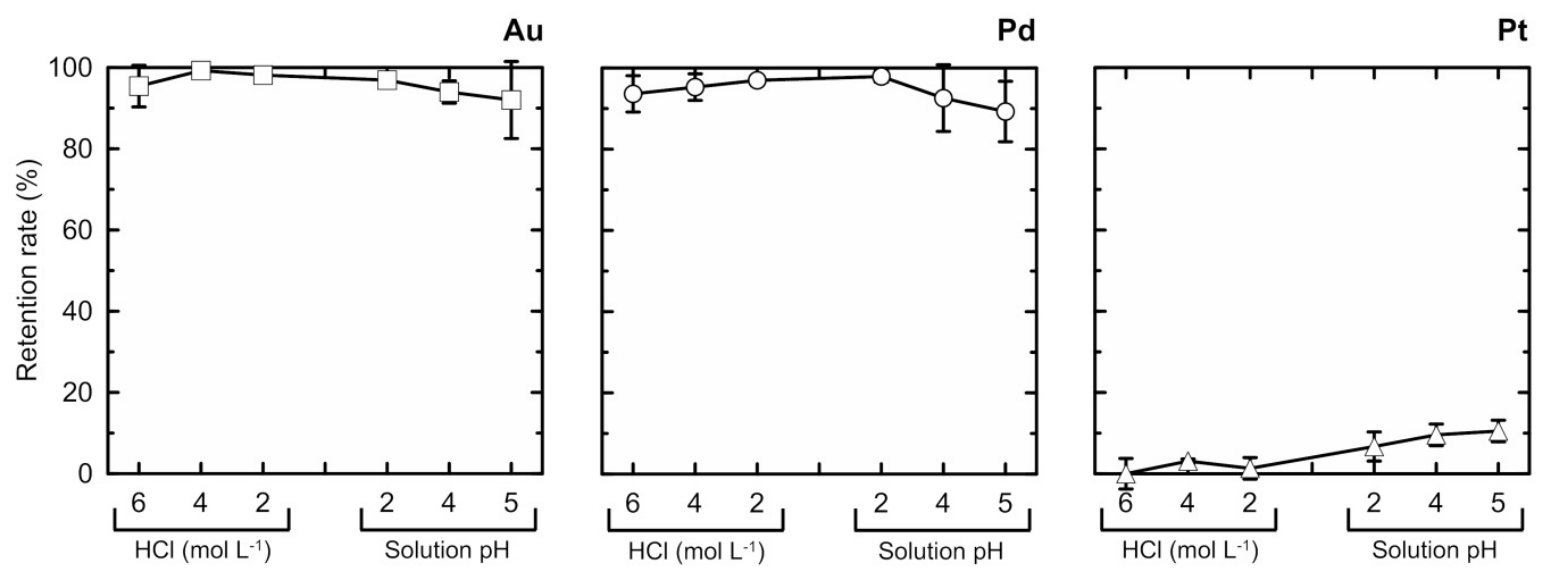

Figure 2: Effect of $\mathrm{HCl}$-induced acidic conditions $(<\mathrm{pH} 2)$ in comparison to the solution $\mathrm{pH}$ (2 to 5) on the retention of $\mathrm{Au}, \mathrm{Pd}$, and Pt in PM-05 SPE-system. Feed solution, Au, Pd and Pt (30 $\left.\mu \mathrm{mol} \mathrm{L}{ }^{-1}\right)$ in $\mathrm{H}_{2} \mathrm{O}$; feed solution volume, $3 \mathrm{~mL}$; loading flow-rate, $3 \mathrm{~mL} \min ^{-1}(n=3)$ 

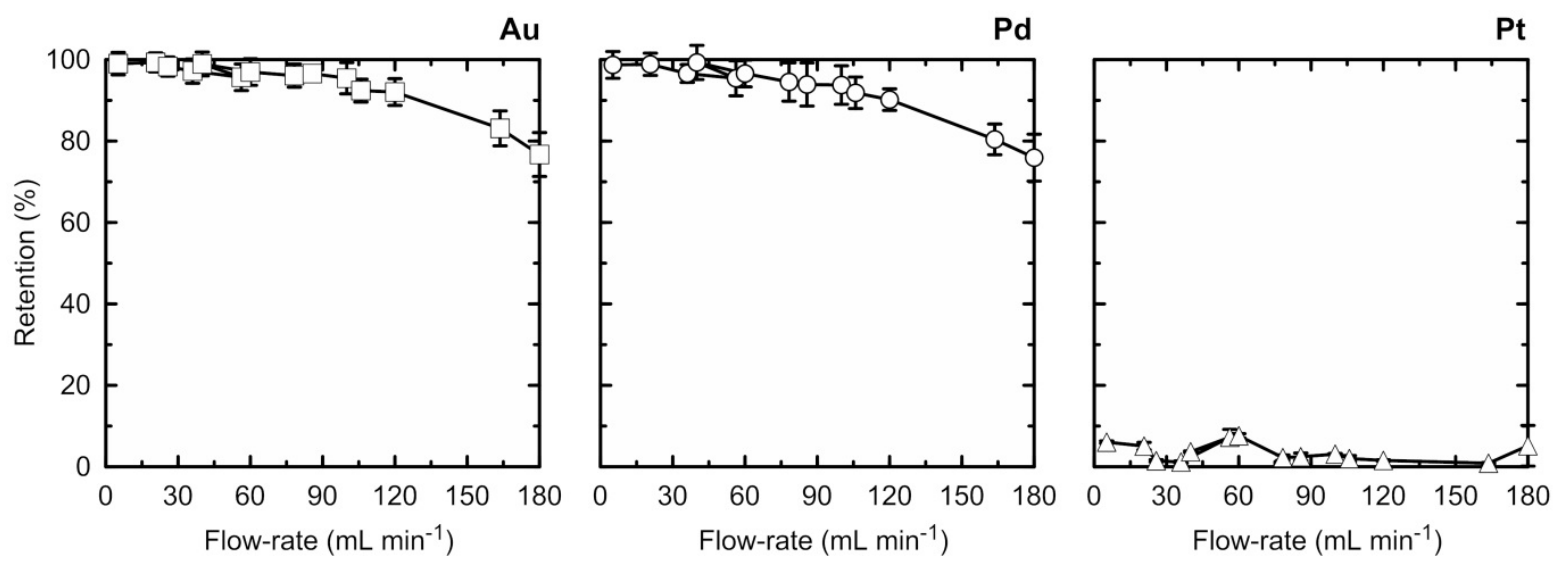

Figure 3: Effect of feed solution flow-rates on the retention of $\mathrm{Au}, \mathrm{Pd}$, and Pt in PM-05 SPEsystem. Feed solution, Au, Pd and Pt $\left(30 \mu \mathrm{mol} \mathrm{L}^{-1}\right)$ in $\mathrm{HCl}\left(1 \mathrm{~mol} \mathrm{~L}^{-1}\right)$; feed solution volume, $3 \mathrm{~mL}$; loading flow-rate, $1-180 \mathrm{~mL} \min ^{-1}(n=3)$ 


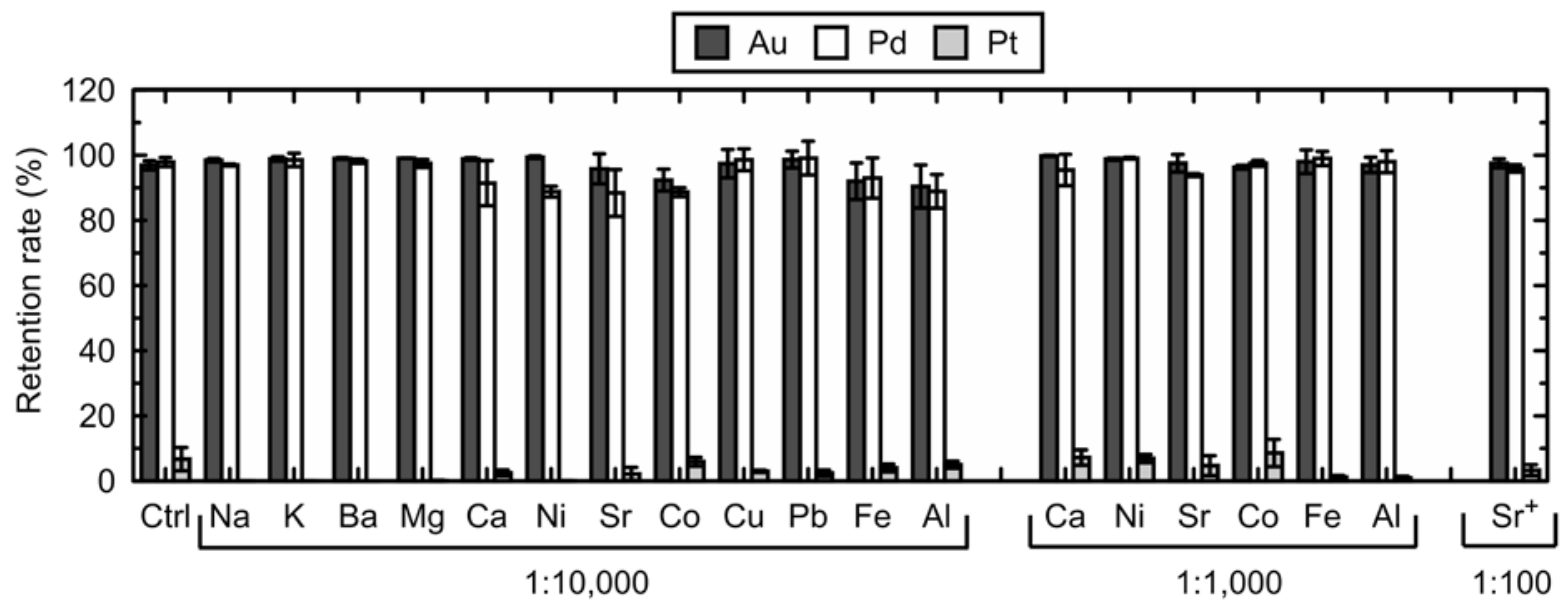

Figure 4: Effect of coexisting elements in the matrix on the retention of $\mathrm{Au}, \mathrm{Pd}$, and $\mathrm{Pt}$ in PM-05 SPE-system. Feed solution, Au, Pd and Pt $\left(30 \mu \mathrm{mol} \mathrm{L}{ }^{-1}\right)$ in $\mathrm{HCl}\left(1 \mathrm{~mol} \mathrm{~L}^{-1}\right)$; content of coexisting analytes in matrix, 3 to $300 \mathrm{mmol} \mathrm{L}^{-1}$; ion to analyte ratio, 1:10,000, 1:1,000, or 1:100; feed solution volume, $3 \mathrm{~mL}$; loading flow-rate, $<50 \mathrm{~mL} \min ^{-1}(n=3)$ 

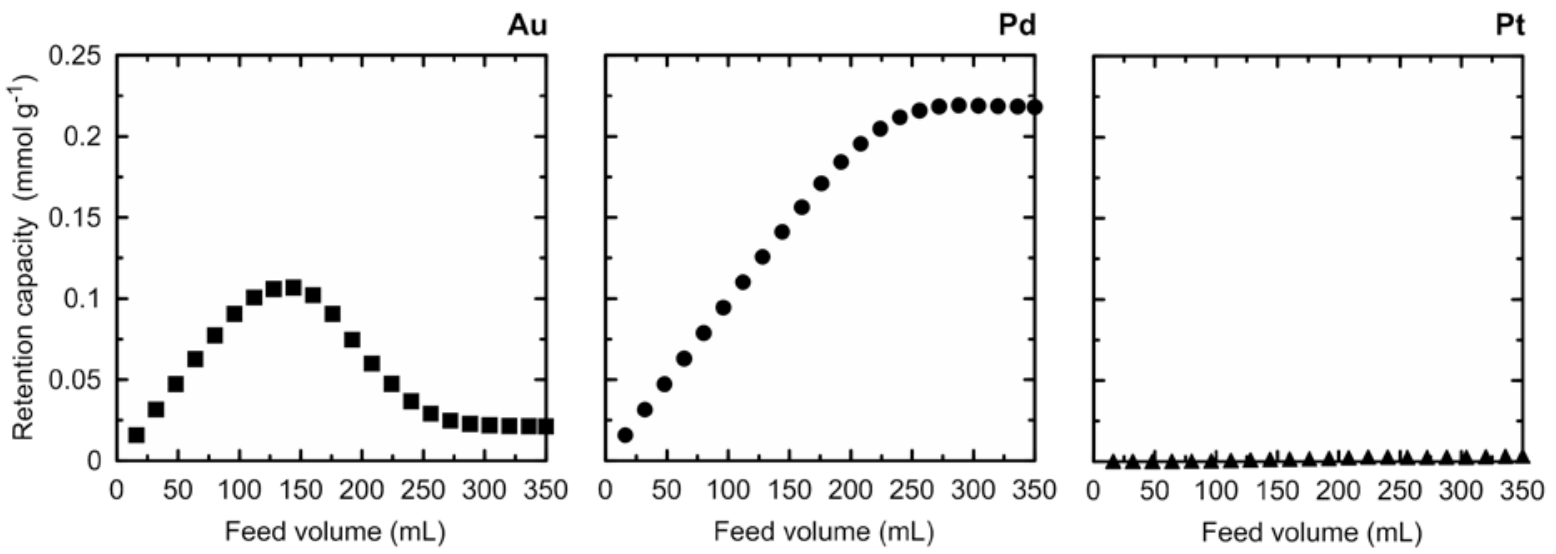

Figure 5: Retention capacity of $\mathrm{Au}, \mathrm{Pd}$, and Pt in PM-05 SPE-system. Feed solution, Au, Pd and Pt $\left(0.5 \mathrm{mmol} \mathrm{L}^{-1}\right)$ in $\mathrm{HCl}\left(1 \mathrm{~mol} \mathrm{~L}^{-1}\right)$; feed solution volume, 0-350 mL; loading flow-rate, $<50 \mathrm{~mL} \mathrm{~min}^{-1}(n=3)$ 


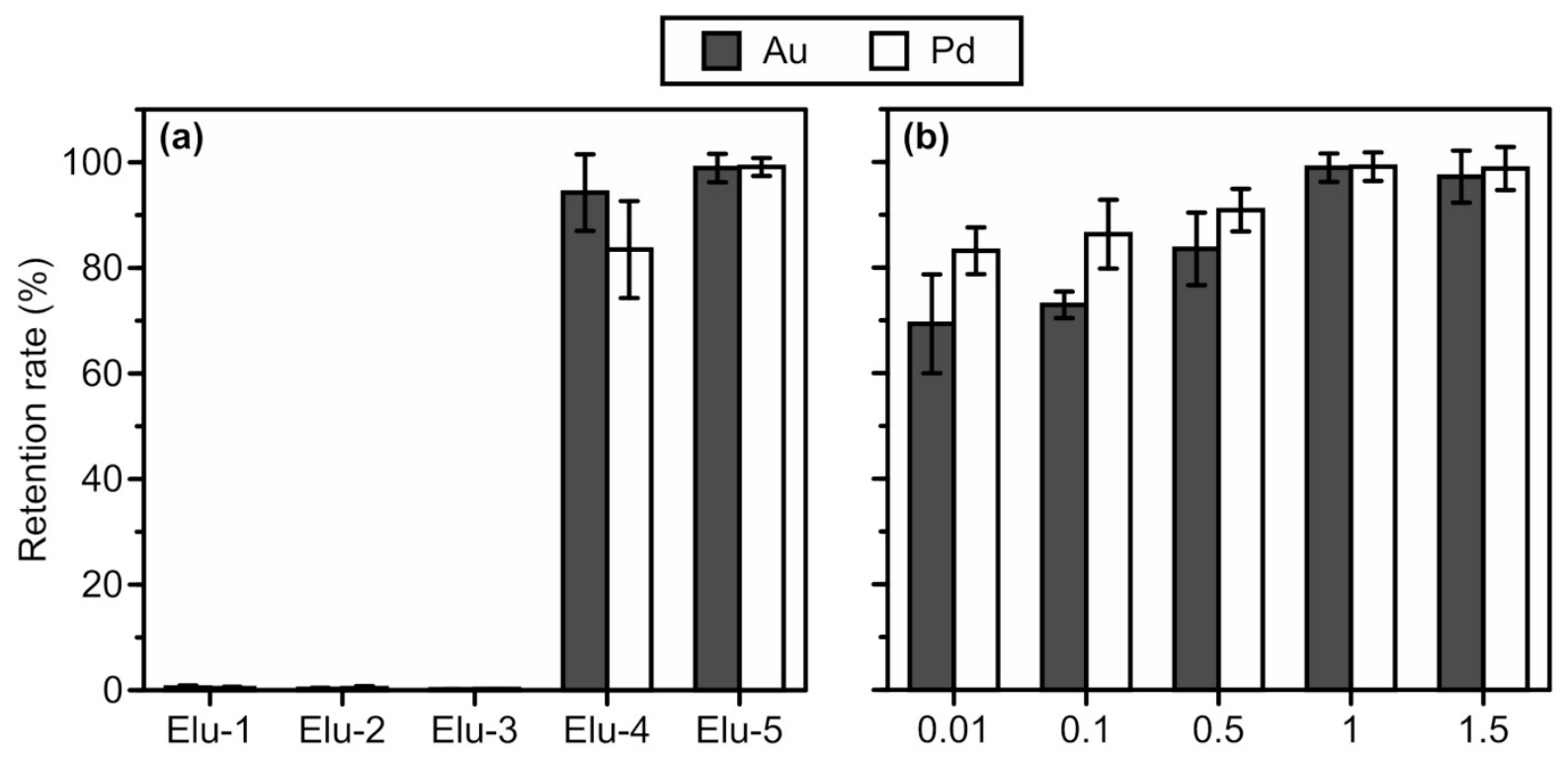

Figure 6: Effect of (a) eluent type (Elu-1, 1 mol L ${ }^{-1} \mathrm{HNO}_{3}$; Elu-2, $1 \mathrm{~mol} \mathrm{~L}^{-1} \mathrm{NH}_{3}$; Elu-3, 1 mol L ${ }^{-1} \mathrm{HCl}$; Elu-4, $1 \mathrm{~mol} \mathrm{~L}^{-1}$ thiourea; Elu-5, $1 \mathrm{~mol} \mathrm{~L}^{-1}$ thiourea in $0.5 \mathrm{~mol} \mathrm{~L}{ }^{-1} \mathrm{HCl}$ ), and (b) thiourea concentration $\left(0.01\right.$ to $\left.1.5 \mathrm{~mol} \mathrm{~L}^{-1}\right)$ in the mixture with $0.5 \mathrm{~mol} \mathrm{~L}^{-1} \mathrm{HCl}$ on the retention of $\mathrm{Au}, \mathrm{Pd}$, and Pt in PM-05 SPE-system. Feed solution, $\mathrm{Au}, \mathrm{Pd}$ and $\mathrm{Pt}(30 \mu \mathrm{mol} \mathrm{L}-$

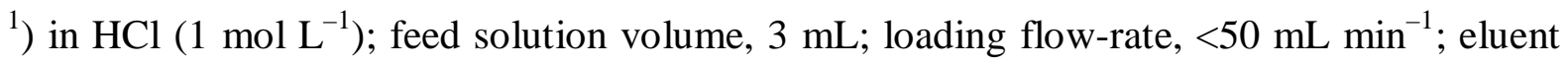
volume, $3 \mathrm{~mL}$; elution flow-rate, $1 \mathrm{~mL} \min ^{-1}(n=3)$ 


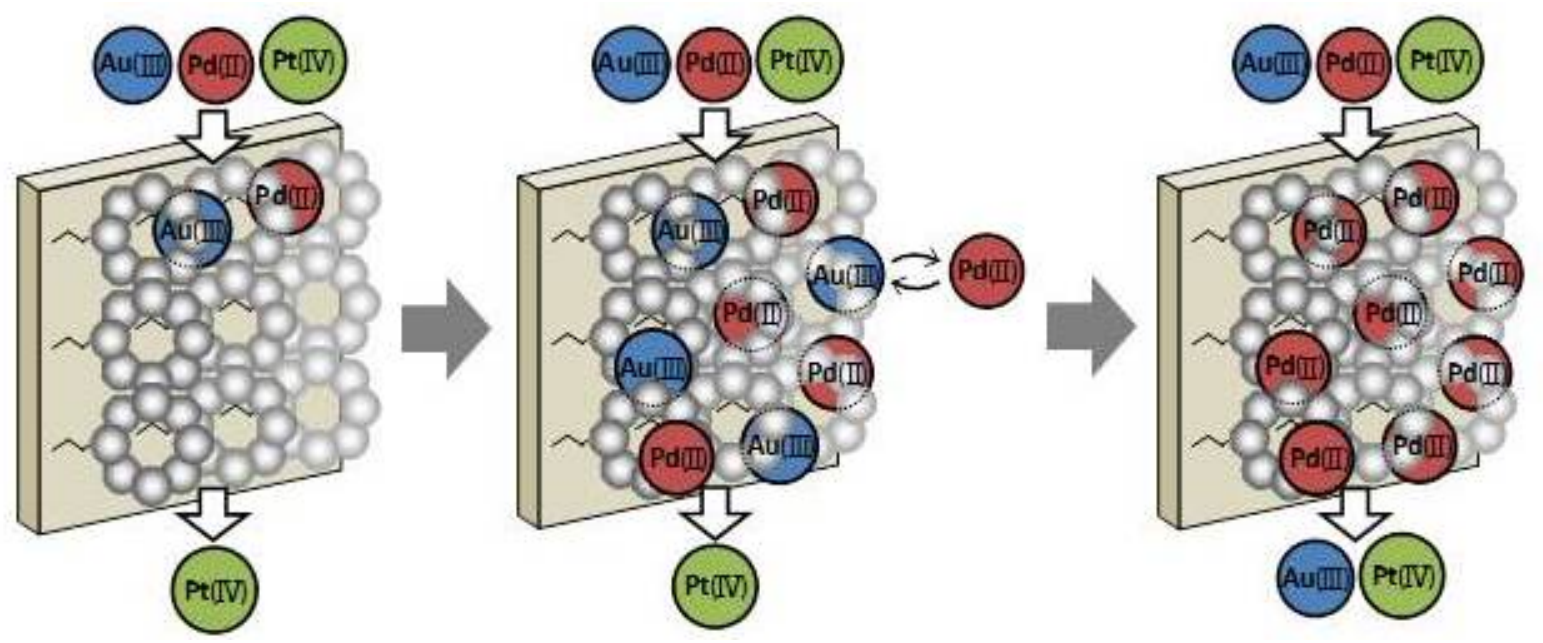

Figure 7: Schematic illustration of the protocol for selective separation of $\mathrm{Au}, \mathrm{Pd}$, and $\mathrm{Pt}$ in PM-05 SPE-system 